San Jose State University

SJSU ScholarWorks

Faculty Publications, Biological Sciences

Biological Sciences

June 2007

\title{
Barriers to Flow: The Effects of Experimental Cage Structures on Water Velocities in High-energy Subtidal and Intertidal Environments
}

Luke P. Miller

Stanford University, luke.miller@sjsu.edu

Brian Gaylord

University of California - Davis

Follow this and additional works at: https://scholarworks.sjsu.edu/biol_pub

Part of the Biology Commons

\section{Recommended Citation}

Luke P. Miller and Brian Gaylord. "Barriers to Flow: The Effects of Experimental Cage Structures on Water Velocities in High-energy Subtidal and Intertidal Environments" Journal of Experimental Marine Biology and Ecology (2007): 215-228.

This Article is brought to you for free and open access by the Biological Sciences at SJSU ScholarWorks. It has been accepted for inclusion in Faculty Publications, Biological Sciences by an authorized administrator of SJSU ScholarWorks. For more information, please contact scholarworks@sjsu.edu. 


\title{
Barriers to flow: the effects of experimental cage structures on water
} velocities in high-energy subtidal and intertidal environments

\author{
Luke P. Miller ${ }^{1, *}$ and Brian Gaylord ${ }^{2}$ \\ ${ }^{1}$ Hopkins Marine Station of Stanford University, Ocean View Blvd, Pacific Grove, CA, \\ 93950, USA. ${ }^{2}$ Bodega Marine Laboratory and Section of Evolution and Ecology, \\ University of California at Davis, P.O. Box 247, 2099 Westshore Road, Bodega Bay, CA \\ 94923, USA. \\ * Corresponding author: 1-831-655-6208, fax 1-831-375-0793, email: \\ contact@lukemiller.org.
}

Correspondence address: Hopkins Marine Station, 120 Ocean View Blvd, Pacific Grove, CA, USA 93950

\begin{abstract}
For decades, marine ecologists have used cages as biological enclosure or exclosure devices to manipulate movement, growth, and survival of organisms. The ability to control the densities of focal organisms makes these structures a powerful tool. However, cages can often produce artifacts that influence the outcome of experiments. Although a subset of these artifacts have been examined previously, the effects of cages on water motion have not been adequately addressed from a quantitative standpoint, especially in high-flow environments. We targeted this data gap by explicitly measuring the fractional degree of velocity reduction inside a variety of experimental cage structures across flow conditions spanning those typical of wave-swept shallow subtidal and
\end{abstract}


intertidal zones. Cages decreased velocities inside by up to $47 \%$ and reduced high-energy impact forces by more than $40 \%$. Associated cage controls, employed to mimic physical effects of cages without interfering with organism movement, often had effects on water flow similar to those of cages. However, the nearly half an order of magnitude change in velocities inside cages and their controls reveals the need to be vigilant in considering potential artifacts, especially those tied to secondary biological interactions. These artifacts may be reduced by maximizing mesh size, employing large plot sizes and low profile structures, using cage controls that best mimic effects of the full cage, and monitoring cage controls to avoid the establishment of high-density "consumer hotels" within them. Using such approaches, researchers can minimize experimental biases and simplify the explanation of experimental results.

Keywords: intertidal zone, subtidal zone, cage effects, artifacts, water flow, waves, velocity, impact force

\section{Introduction}

Cages have been used for decades in ecological field experiments on rocky intertidal shores and in shallow subtidal habitats. Their primary purpose is usually to manipulate the presence, absence, or densities of mobile predators and grazers, typically with the goal of evaluating biological interactions (e.g., Connell, 1961a; 1961b; 1970; Dayton, 1971; Haven, 1973; Menge, 1976; Hall, et al., 1990; Navarrete, 1996; Berlow, 1997; Hindell, et al., 2001; Tomanek and Sanford, 2003; Bertness, et al., 2004; Menge, et al., 2004). 
As is well recognized, however, experimental artifacts can be induced by the presence of a cage or similar structure. Cages often reduce water flow, decrease solar insolation, retard air movement, and potentially change behavior of organisms (Connell, 1974; Virnstein, 1978; Dayton and Oliver, 1980; Hall, et al., 1990). Good experimental design therefore dictates that procedures be employed to gauge the effect of the experimental protocol itself on the outcome of the experiment (Underwood, 1997; Quinn and Keough, 2002). For this reason, cage controls are normally deployed alongside treatment cages, accompanying unmanipulated control plots. The assumption is that the cage controls appropriately mimic the physical effects of the cage without providing a barrier to the movement of mobile organisms. While a cage typically consists of a foursided structure with or without a top (a "full cage" or a "fence," respectively), cage controls are often configured as incomplete fences (i.e., with gaps or missing sides) or as "roofs" (mesh tops with at least one open side).

Effects of cages and cage controls on light levels and temperature have been addressed and directly measured by several researchers, and are often predictable if the topography of the site is considered in the context of solar angles (e.g., Connell, 1974; Paine, 1977; Dayton and Oliver, 1980; Hayworth and Quinn, 1990; Tomanek and Sanford, 2003). However, the effects of cage structures on water flow, while recognized (e.g., Connell, 1974; Dayton and Oliver, 1980; Leber, 1985; Keuskamp, 2004) have been studied primarily only in a qualitative fashion, especially in energetic flow environments. Such qualitative observations suggest increased rates of sedimentation due to reduced flow, especially in soft-bottom benthic studies (Virnstein, 1977, 1978; Peterson, 1979; Dayton and Oliver, 1980; Hulberg and Oliver, 1980; Olafsson, et al., 1994; but see 
Como, et al., 2006 and Reise, 1985), effects on settlement and feeding of benthic animals (Schmidt and Warner, 1984), and lower risks of dislodgement for enclosed organisms (van Katwijk and Hermus, 2002).

Clearly, it is possible for experimental structures to alter the pattern and intensity of flow over experimental plots. Thus, cage controls are vital for elucidating artifacts created by the presence of experimental structures. However, it is possible for artifacts to arise even in cases where cage controls exactly mimic the flow effects of a cage. If velocities are identical between the two treatments, but retarded relative to the outside flow, and if a cage-excluded predator or grazer prefers regions of reduced flow, consumers may move into the cage control and remain at higher than natural densities (Strasser, 2002). In this situation, although the flow effects of the cage are correctly modeled by the cage control, higher consumer densities relative to unmanipulated plots indicates that biological interactions may be misrepresented.

Artifacts associated both with cages and cage controls are likely to become enhanced as the degree of flow disruption by cages increases. Such issues are most relevant in environments where water motion has large effects, such as in regions characterized by rapid wave-driven flows that act as major agents of disturbance (Sousa, 2001). Our goal in the present study, therefore, is to directly evaluate the effects of cage structures on the rapid flows typical of shallow subtidal and wave-swept intertidal zones. Using a variety of cage sizes and designs, we measure velocities and flow forces imposed on standard objects inside and outside of cages and cage controls. We address three primary questions: 1) What is the degree of flow attenuation in experimental cages with different sized mesh, 2) are full cages, fences, and roofs likely to alter flow in their 
interiors in predictably different ways, and 3) do cages of various designs function differently in subtidal and intertidal flow regimes? Our findings, while not comprehensive, provide quantitative evidence of the extent to which cage structures act as imperfect solid bodies, an effect that causes deflection of flow around them and produces measurable reductions in flow even with large mesh sizes. The potential effects of this velocity reduction on the organisms enclosed within cage structures are discussed in the context of ecological field manipulations.

\section{Materials and methods}

Cages used in these experiments represent several variations on the standard wire mesh cage employed by generations of researchers. Stainless steel wire mesh, either woven or welded, is available from a variety of industrial suppliers, and allows researchers to construct robust, long-lasting structures that can withstand harsh field conditions with minimal maintenance. The most common mesh has square openings and is sold in terms of the size of the opening (or openings per inch in the U.S.). Our meshes had wire diameters of $1.2 \mathrm{~mm}$ and openings with nominal widths of $23 \mathrm{~mm}, 11.5 \mathrm{~mm}, 7$ $\mathrm{mm}, 5 \mathrm{~mm}$, and $3 \mathrm{~mm}$ (corresponding to 1, 2, 3, 4, and 6 openings per inch respectively). The percentage of mesh area that is open to flow is $85 \%$ for $23 \mathrm{~mm}$ mesh, $82 \%$ for 11.5 $\mathrm{mm}$ mesh, $74 \%$ for $7 \mathrm{~mm}$ mesh, $66 \%$ for $5 \mathrm{~mm}$ mesh, and $52 \%$ for $3 \mathrm{~mm}$ mesh.

We constructed several cage structures using the five sizes of mesh. "Full cages" were structures with four mesh sides and a mesh top, which effectively enclose organisms inside and prevent entry or exit of animals larger than the mesh dimensions. "Fences" had four mesh sides, but no top, enabling organisms to enter or exit through the top of the 
structure, but preventing their movement along the substrate through the mesh sides.

"Roofs" had two opposing mesh sides and a mesh top. The remaining two sides of the roof structure were open, allowing free exchange of organisms, either by crawling along the substrate or swimming, as well as unrestricted water flow through the open sides. Due to experimental limitations, not every mesh-size and cage-style combination was tested in every situation.

\section{Subtidal measurements of cage effects on flow}

The effects of full cages, fences, and roofs on flows in their interior were examined beneath non-breaking waves in subtidal locations in the field on November 9 , 2004 and June 20, 2005. On each measurement date, cage structures were fixed to the housing of a three-axis drag-sphere flow probe (constructed following the general design of Gaylord, 1999; 2000) such that the cage structure enclosed the $2.54 \mathrm{~cm}$ diameter drag sphere. This apparatus was deployed in the shallow subtidal zone at a depth of approximately $2 \mathrm{~m}$ on a flat sandy region of seafloor. The base of the cage structure was carefully aligned flush against the substratum, with the sensing height of the drag sphere probe $3 \mathrm{~cm}$ above the seafloor, characteristic of elevations to which many invertebrates and macroalgae protrude. The voltage signal from the drag sphere probe was carried via cable to a boat moored $50 \mathrm{~m}$ away, where it was amplified, passed through an analog-todigital converter, and digitally sampled at $5 \mathrm{~Hz}$ for storage on a laptop computer.

An acoustic Doppler velocimeter (ADV; Nortek USA) was concomitantly deployed to measure the three components of velocity outside the cage at the same height as the drag sphere, but at a location $40 \mathrm{~cm}$ away along a line parallel to the wave crests. 
This configuration positioned the ADV away from the region where flow would be disrupted by the cage, but close enough to ensure spatial and temporal coherence of the incident velocity field. The ADV also measured pressure, enabling calculation of seasurface fluctuations associated with waves passing overhead. It recorded internally at a factory-fixed rate of $16 \mathrm{~Hz}$.

Each of the cage structures had footprints of $15 \times 20 \mathrm{~cm}$. They were oriented with the long axis of the structure facing into the direction of wave propagation. In the case of the roofs, the mesh sides faced into the waves. The cages and roofs were $10 \mathrm{~cm}$ tall, and the fences were $8 \mathrm{~cm}$ tall. For each cage structure deployed in the field, 6000 to 15,000 velocity points were recorded, after which the structure was retrieved by divers and replaced with the next structure.

The November experiment occurred on a day with exceptionally clear water. As a consequence, the acoustic return signal for the ADV was weak and the velocity records exhibited sporadic spiking. A simple central difference algorithm was therefore applied during analysis to identify and remove all spurious points. This issue did not arise during the June experiment. To place the ADV and drag sphere records on a common time sequence, the $16 \mathrm{~Hz} \mathrm{ADV}$ records were linearly interpolated onto the $5 \mathrm{~Hz}$ time points of the drag sphere probe. Both records were rotated into their principal coordinates and the drag sphere voltage signal was converted to velocity according to previously conducted laboratory calibrations. Velocities inside the cage structures, as measured by the drag sphere, were then regressed against the outside velocities measured by the ADV. Major Axis regression techniques were used due to the two instruments' comparable level of error (Sokal and Rohlf, 1995). 


\section{$\underline{\text { Laboratory experiments with unidirectional high flow speeds }}$}

The effects of cages on water flow at the higher velocities found in the intertidal zone were tested in the laboratory. The laboratory experiments used a gravity-driven water cannon to deliver a single shot of water to a drag element (a $2.54 \mathrm{~cm}$ diameter sphere with $2 \mathrm{~mm}$ roughness elements as in the subtidal experiments) attached to an electronic force transducer that could have a cage mounted over it. The resulting impactstyle flows produced by this apparatus resemble in broad strokes those associated with the initial impingement of breaking waves, shown by Gaylord (2000) to be responsible for many of the largest forces imposed on intertidal organisms. The water cannon consisted of a $10.1 \mathrm{~cm}$ (4 inch) diameter plastic plumbing pipe attached vertically to the side of a building (Fig. 1). The upper section of the pipe was filled with water that was held at an elevated position by means of a sliding valve, which obstructed the lower section of the pipe. This sliding valve could be rapidly opened (via a pneumatic cylinder) to allow the water to fall out of the upper section of pipe. Upon descending, a large-radius pipe elbow redirected the flow into a horizontal plane. An experimental test section was mounted at the end of the pipe elbow, together with mounts for the electronic force transducer and cage structures. By changing the height of the vertical pipe segments between the valve and elbow (from $0.8 \mathrm{~m}$ to $5.7 \mathrm{~m}$ ), the speed of the water as it exited the pipe and impacted the cage structure and enclosed drag element could be adjusted.

The force transducer attached to the drag sphere employed four foil strain gages to measure the displacement of coupled, parallel cantilever beams in response to applied force. Because only the drag sphere protruded into the experimental test section, flow did 
not interact with other portions of the force transducer (see inset, Fig. 1). Signals from the force transducer were amplified, digitally sampled by computer at $6,000 \mathrm{~Hz}$, and filtered through a $20^{\text {th }}$ order Chebyshev II infinite-impulse response filter routine implemented using Matlab ${ }^{\circledR}$ software. The filter removed noise occurring above a cutoff frequency of $200 \mathrm{~Hz}$ without introducing changes in the amplitude or phase of the signal below that frequency. This cutoff frequency was well below the natural frequency of the transducer $(660 \mathrm{~Hz})$. The maximum voltage for each trial was then extracted from the data and converted to force based on prior calibrations of the transducer.

In presenting results from the water cannon tests, we report both hydrodynamic impact forces per se, as well as water velocities responsible for the impact events, since the latter aids in comparison to the subtidal findings. The velocity of water incident at the test section prior to entering a cage was calculated by treating the column of water in its ready position as a single body with its center of mass at a height $H$ above the test section. The potential energy of this column of water, Hmg, is converted to kinetic energy, $\frac{1}{2} m V^{2}$ when the valve opens and the water falls, such that

$$
H m g=\frac{1}{2} m V^{2}
$$

where $m$ is the mass of the water, $g$ is the acceleration due to gravity, and $V$ is the velocity of the water as it exits the end of the pipe and impinges on the test section. Equation 1 can be rearranged to solve for this velocity

$$
V=\sqrt{2 g H}
$$

The velocities calculated in this manner were validated using a high speed video camera to measure the distance traveled by fluid parcels in the working section between frames 
and using a K-band radar gun (Stalker ATS) aimed at the water exiting the working section. The known water velocities were then linked to the impact-type forces imposed on the unobstructed drag sphere (i.e., without a cage structure in place) at each velocity by fitting a power curve to the plot of velocity, $V$, versus force, $F$ :

$$
V=3.043 F^{0.624}
$$

This relationship (with force in Newtons and velocity in $\mathrm{m} \mathrm{s}^{-1}$ ) was used in all subsequent analyses to calculate water velocity from the impact force acting on the drag sphere probe when it was located inside cage structures of varying designs.

Five mesh sizes and two cage styles (full cage and roof) were tested using the water cannon at each of four water speeds $\left(5.1 \mathrm{~m} \mathrm{~s}^{-1}, 6.8 \mathrm{~m} \mathrm{~s}^{-1}, 10 \mathrm{~m} \mathrm{~s}^{-1}, 11.6 \mathrm{~m} \mathrm{~s}^{-1}\right)$, spanning flows common to intertidal regions of many wave-exposed rocky shores (Denny, et al., 2003; Helmuth and Denny, 2003). The structures were built to external dimensions of $10 \mathrm{~cm}$ on a side and a height of $3.8 \mathrm{~cm}$; these dimensions are different from those of the subtidal cages but are also common for cages employed in ecological studies. The roof structures were arranged so that one of the mesh sides of the roof faced the oncoming water stream. Preliminary tests using the open side of the roof facing the oncoming water showed no effect on flow compared to the structure-absent condition, so this orientation was not tested further. In all other runs, each structure was tested 10 times at each water speed, and the average force resulting from those runs is presented here. ANOVA comparisons of the effect of mesh size and structure style were carried out using SYSTAT 8.0 software.

$\underline{\text { Intertidal field experiment }}$ 
Intertidal field tests of cages and cage controls were conducted along the rocky shoreline at Hopkins Marine Station in Pacific Grove, California. A vertical rock wall on the most wave-exposed portion of the shore was drilled to mount a number of maximum force recorders (a.k.a. dynamometers) with $2.54 \mathrm{~cm}$ diameter drag spheres, each textured with $2 \mathrm{~mm}$ roughness elements (Denny and Wethey, 2001).

The maximum force recorders were deployed within cage structures bolted over them against the rock face. The cage structures were large enough to allow unrestricted movement of the drag sphere inside. Maximum force recorders were checked and reset during low tide when sea conditions allowed access to the site, as often as once per day, with an average time between checks of 3 days. Every site and treatment had at least 16 force measurements, with a maximum of 27 for certain site/treatment combinations. The four structures were first set out in November, 2001, and measurements continued through March, 2003. The four structures were then set out at four new sites in March, 2003, and measurements continued through July, 2003. During periods when a site did not have a cage structure installed, maximum wave forces were recorded at the same intervals as the sites with structures installed. These maximum forces were used as the control data for each site. Significant wave height was recorded every six hours at a site 50 meters offshore of the intertidal site throughout the entire duration of the measurements using a Seabird SBE26 wave gauge, mounted at $10 \mathrm{~m}$ depth.

Three styles of field structures were deployed. We used two sizes of full cages constructed of 3-mm mesh: a "small cage" measuring $10 \mathrm{~cm}$ on a side, and a "big cage" measuring $15 \mathrm{~cm}$ on a side. A two-sided roof structure made of 5-mm mesh, measuring $15 \mathrm{~cm}$ on a side, and a four-sided, open-topped fence structure constructed of 5-mm mesh 
with $15 \mathrm{~cm}$ sides were also used. All structures were $5 \mathrm{~cm}$ tall except for the fence structure, which was $6.5 \mathrm{~cm}$ tall. Although these structures represent only a subset of the sizes and styles used in other portions of this study, the logistics of accessing the experimental site and making measurements precluded the use of more structures.

Maximum force recordings for each site were analyzed separately due to differences in topography and wave exposure between sites. Time periods in which the waves were too small to exceed the baseline sensitivity of the maximum force recorder had zeroes substituted for the missing force measurement.

\section{Results}

$\underline{\text { Subtidal measurements of cage effects on flow }}$

Wave conditions during the first subtidal field trial were characterized by a significant wave height of $0.37 \mathrm{~m}$ and a dominant wave period of $12 \mathrm{~s}$. The significant wave height and dominant wave period were $0.46 \mathrm{~m}$ and $16 \mathrm{~s}$, respectively, during the second field trial. These conditions produced velocities at the location of the sensors that ranged from near-zero to approximately $1.25 \mathrm{~m} \mathrm{~s}^{-1}$, oscillating bi-directionally along a cross-shore axis. There was no appreciable longer-term current during the field measurements.

The drag sphere probe and ADV recorded similar velocities in the absence of a cage structure. A linear regression between drag sphere and ADV velocities exhibited a slope of 0.98 , not significantly different from 1.0 (Fig. 2a). This finding indicates that both instruments measured the same incident flow field. In contrast, velocities within full cages exposed to subtidal flows were significantly attenuated relative to velocities 
outside, for all mesh sizes examined (Fig. 2b-2e). In the case of a 23-mm mesh, velocities inside a full cage were reduced to $88 \%$ of those outside. Flows inside a 3-mm full cage were reduced substantially, to $53 \%$ of those outside. The degree of velocity reduction was also nearly identical in full cage, fence and roof structures (Figs. 3, 4). The degree of flow attenuation for subtidal cages also appears to be linearly related to the percentage of open area in each of the meshes (Fig. 5). The relationship is not significantly different for the full cages, fences, and roofs (ANCOVA; $\mathrm{F}_{2,17}=0.0007, \mathrm{p}>0.05$ for differences among slopes; $F_{2,19}=0.005, \mathrm{p}>0.05$ for differences among intercepts).

\section{$\underline{\text { Laboratory experiments with unidirectional high flow speeds }}$}

Mesh size had a significant effect on forces measured under cages and roof treatments compared to control conditions at every water speed tested (Table 1). Tukey post-hoc tests of measured force within each water speed treatment show different mesh sizes created differing magnitudes of force reduction, with the largest mesh sizes resulting in the least attenuation of forces $(\sim 10-12 \%)$, and the smallest mesh sizes creating the greatest reduction in forces measured ( $45 \%$, Fig. 6). Analogously, velocities inside cages were reduced 15 to $34 \%$ compared to control conditions (Fig. 7). Although the values are not directly comparable with the subtidal data (Figs. 2, 3) due to differences in cage size and the nature of the impinging flow, the same pattern of increasing attenuation of velocities with decreasing mesh size holds.

The results of the ANOVA test of structure style on impact force showed little difference between cages and roofs (Table 2). In half of the comparisons there was no significant effect of structure type (cage vs. roof). In the other half, there were significant 
differences, but the absolute difference in magnitude was quite small $(0.13 \mathrm{~N} \pm 0.15)$ and may be of little real-world importance, especially compared to differences between the structure and no-structure situations (Fig. 6).

$\underline{\text { Intertidal field experiment }}$

The structures deployed in the intertidal zone had varying effects on water flow beneath them. ANCOVA analyses demonstrated that each structure had homogeneous slopes of the regression of force as a function of offshore wave height. In the test of the main treatment effect of the presence of a structure, each of the four structures had a significant effect on interior water flow during the March - July 2003 deployment but no significant effect during the November, 2001 - March, 2003, deployment (Fig. 8; Table 3). The difference in results was not due to a difference in offshore wave heights between the two time periods (1-way ANOVA, $\left.\mathrm{F}_{1,49}=0.271, \mathrm{p}=0.605\right)$.

\section{Discussion}

Past research involving cages in the subtidal and intertidal zones has considered flow artifacts almost exclusively from a qualitative or correlative perspective, in fairly benign habitats only (i.e. measuring rates of sediment deposition, Hulberg and Oliver, 1980; Woodin, 1981). Even the few studies that have actually measured flows within cages have done so in an extremely limited fashion (Lassig, 1982; Kennelly, 1991). Our experiments therefore provide a first targeted, laboratory and field evaluation and 
comparison of flow effects inside cages spanning a spectrum of designs and mesh sizes, under the more severe flows conditions that characterize wave-swept shores.

The quantitative measurements of our study demonstrate that water velocities within wire mesh structures can be dramatically reduced compared to surrounding freestream velocities. Smaller mesh sizes substantially reduce water velocities, cutting speeds in the subtidal zone by as much as $50 \%$, reducing water speeds in the intertidal zone by $15-34 \%$ and reducing impact forces in the intertidal zone by over $40 \%$. However, data from the field-deployed maximum force recorders demonstrate that effects of cages are not entirely predictable. In the turbulent environment of wave-swept rocky shores, smallscale topographical variation can cause local modulation of flow, which can limit predictability on a site-specific basis and may pose problems for the interpretation of studies in such areas (Gaylord, 2000; Denny, et al., 2003; Helmuth and Denny, 2003; Denny, et al., 2004).

There can be substantial differences in flow attenuation inside various styles of structures. While full cages should have reasonably consistent effects across a variety of flow directions, the effects of a two-sided roof structure will be much less predictable by virtue of the design of the structure. Depending on whether the mesh or open side faces into flow, there could be no flow attenuation or a 10 to $30 \%$ reduction in water velocity. An a priori knowledge of the effect of the structure will therefore be difficult wherever flows are highly turbulent or variable in direction, such as on wave-swept shores (Denny, 1985), especially given recently documented subtleties of oscillatory boundary layers (Lowe, et al., 2005). However, at sites where there is a demonstrably uni-directional flow pattern (e.g., tidal channels), the researcher can orient these structures appropriately. 
Aside from such inescapable issues of flow directionality, our results demonstrate that cages of various designs can function similarly in shallow subtidal and intertidal environments, with absolute magnitudes of structure-associated flow reductions varying linearly with the open fraction of the mesh. Even the largest mesh size $(23 \mathrm{~mm})$ has a significant effect. Thus, in the shallow subtidal zone, where measured velocities due to orbital wave motion often peak at around $1 \mathrm{~m} \mathrm{~s}^{-1}$, maximum velocity reductions of 20-30 $\mathrm{cm} \mathrm{s}^{-1}$ can arise inside a structure. Further up the shore, where velocities in the waveswept rocky intertidal zone reach $20 \mathrm{~m} \mathrm{~s}^{-1}$ (Denny, et al., 1985; Bell and Denny, 1994; Denny, 1995; Denny, et al., 2003), a 30\% reduction (3 $\mathrm{mm}$ mesh) could reduce flows inside a cage by $6 \mathrm{~m} \mathrm{~s}^{-1}$ relative to those outside.

The reduction in flow measured in the center of cage or fence structures may be magnified when organisms are just inside their edges. Although we have not measured the effect directly, the fluid dynamics literature gives us a useful analogy to this situation, based on the study of the effects of terrestrial windbreaks. When porous fences are set up to act as windbreaks, researchers observe a separation of air flow over the top of the fence, resulting in a "quiet zone" in the lee of the fence. This quiet zone of air extends from the fence line out to distances of 4 to 8 times the height of the fence (Heisler and Dewalle, 1988; McNaughton, 1988; Hipsey and Sivapalan, 2003). A similar effect likely occurs with water flowing through and over our experimental fences. When considering a full cage with a mesh roof, it is unclear whether the "quiet zone" established by the wall of the cage will attenuate in the same manner as in the open-topped fence example.

\section{$\underline{\text { Ecological effects of cages }}$}


It remains the researcher's responsibility to determine if configuration (i.e., cage style) or habitat (i.e., subtidal or intertidal) will have important biological consequences for their particular study system, but there are certainly cases where cages could have consequences by providing a refuge from large wave forces (Miller, 1974; Menge, 1978, van Watwijk and Hermus, 2002; Denny, 1995; Trussell, 1997). While explicit tests of dislodgement rates are scarce in the literature, there are many anecdotal observations of cage structures altering densities of mobile consumers, including limpets and whelks (Navarrete, 1996), polychaetes and juvenile seastars (Berlow, 1997), small gastropods (Kennelly, 1983), and nemertean worms and opisthobranchs (Dayton, 1971). Cage structures can also reduce incidence rates of rapid flow and thereby change the amount of time available for foraging by organisms that run a greater risk of dislodgement while actively moving (Menge, 1974; Menge, 1976; Burrows and Hughes, 1989; Denny and Blanchette, 2000). In other situations, increased rates of sedimentation in cages can alter community structure (Virnstein, 1977; Hulberg and Oliver, 1980; Menge, et al., 1986).

\section{$\underline{\text { Cage controls }}$}

As alluded to in the Introduction, because cage controls alter flow but do not exclude mobile organisms, consumers can find refuge from high water velocities inside control structures (Strasser, 2002). This feature has the potential to lead to situations where the density of the consumer species is higher than in the natural control plots (and the caged plots from which it is excluded). Thus, even when a cage control functions as a good physical mimic for the effects of a full cage, it may simultaneously function as a poor biological control. Dayton and Oliver (1980) suggest that a proper cage control in 
this situation might involve manually reducing densities of the excluded consumers in cage controls down to a level equal to the densities in natural control plots.

Other types of control plots may have additional challenges. For example, the utility of pure roof structures (i.e., ones that are supported by posts and entirely lack sides; Connell, 1974; Navarrete, 1996; Berlow, 1997) as cage controls in high flow conditions is called into question by our results. While these roofs do recreate the light attenuation effects of a full cage, their ability to mimic the alteration of flow and desiccation inside a full cage is suspect. The elevated mesh roof may therefore create a third type of manipulation which will complicate the interpretation of the effects of the main experimental cage on the system.

\section{$\underline{\text { Conclusions and recommendations }}$}

The data presented here demonstrate, as long suspected, that flow modifications created by cages could have substantial effects on some experimental systems. A reasonably conservative, quantitative estimate of the degree of velocity attenuation inside cages of given mesh size can be extracted from Fig. 3. Although changes in flow conditions will not have consistent effects across all taxa and systems, requiring field ecologists to evaluate how results presented here may impact the outcome of their particular study, we can make some broad recommendations for minimizing cage artifacts.

1) Maximize the mesh size. Whereas a large $23 \mathrm{~mm}$ mesh opening reduces flows by $2 \%$ to $18 \%$, a $3 \mathrm{~mm}$ mesh opening can reduce flow by $30 \%$ to $49 \%$ in high-flow conditions. When small mesh sizes are necessary to exclude smaller organisms, employ the precautions listed below. 
2) Design low-profile structures and maximize plot size, preferably using lateral dimensions that are at least 10 times the height to minimize edge effects. Consider shorter fences (in cases where the focus is on control of crawling organisms) rather than full cages to allow wave-driven flows to impinge unobstructed from above.

3) If cage controls have open sides, orient them appropriately to mimic physical effects of full cages. Generally, the complete mesh sides should face into oncoming flow to create velocity reductions similar to those inside the full cage.

4) Monitor densities of mobile consumers in cage controls to avoid the "hotel" effect, where large numbers of consumers enter a cage control to seek shelter. It may be necessary to manipulate the density of consumers in cage controls to match densities in natural controls.

5) When possible, actually measure inside versus outside flow differences. This approach may be critical for separating physical and biological effects in situations where flow rates are known to directly influence growth rates or other characteristics of organisms.

6) For older datasets, be wary of results that indicate differences between cage controls and both natural control plots and full cages. These trends could be the result of cage controls altering consumer densities by creating a unique microhabitat.

\section{Acknowledgements}

We would like to thank M. W. Denny and three anonymous reviewers for their suggestions on improving the manuscript. This work was supported by National Science Foundation grants OCE-0241447 and OCE-9985946, and is contribution number 2370 
from the Bodega Marine Laboratory, University of California at Davis. This is contribution number 241 from PISCO, the Partnership for Interdisciplinary Studies of Coastal Oceans funded primarily by the Gordon and Betty Moore Foundation and the David and Lucile Packard Foundation. 


\section{References}

Bell, E.C., Denny, M.W., 1994. Quantifying "wave exposure": a simple device for recording maximum velocity and results of its use at several field sites. J. Exp. Mar. Biol. Ecol. 181, 9-29.

Berlow, E.L., 1997. From canalization to contingency: Historical effects in a successional rocky intertidal community. Ecol. Monogr. 67, 435-460.

Bertness, M.D., Trussell, G.C., Ewanchuk, P.J., Silliman, B.R., Crain, C.M., 2004. Consumer-controlled community states on Gulf of Maine rocky shores. Ecology 85, 1321-1331.

Burrows, M.T., Hughes, R.N., 1989. Natural foraging of the dogwhelk, Nucella lapillus (Linnaeus) - the weather and whether to feed. J. Mollus. Stud. 55, 285-295.

Como, S., Rossi, F., Lardicci, C., 2006. Caging experiment: Relationship between mesh size and artifacts. J. Exp. Mar. Biol. Ecol. 335, 157-166.

Connell, J.H., 1961a. Influence of interspecific competition and other factors on distribution of barnacle Chthamalus stellatus. Ecology 42, 710-723.

Connell, J.H., 1961b. Effects of competition, predation by Thais lapillus, and other factors on natural populations of the barnacle Balanus balanoides. Ecol. Monogr. 31, 61-104.

Connell, J.H., 1970. A predator prey system in the marine intertidal region Part 1: Balanus glandula and several predatory species of Thais. Ecol. Monogr. 40, 4978.

Connell, J.H., 1974. Ecology: field experiments in Marine Ecology. In: Mariscal, R.N. (Ed.), Experimental Marine Biology. Academic Press, New York, pp. 21-54.

Dayton, P.K., 1971. Competition, disturbance, and community organization - Provision and subsequent utilization of space in a rocky intertidal community. Ecol. Monogr. 41, 351-389.

Dayton, P.K., Oliver, J.S., 1980. An evaluation of experimental analyses of population and community patterns in benthic marine environments. In: Tenore, K.R., B.C. Coull (Eds.), Marine Benthic Dynamics. University of South Carolina Press, Columbia, pp. 93-120.

Denny, M., Wethey, D., 2001. Physical processes that generate patterns in marine communities. In: Bertness, M.D., S.D. Gaines, M.E. Hay (Eds.), Marine Community Ecology. Sinauer Associates, Inc., Sunderland, Massachusetts, pp. 337.

Denny, M.W., 1985. Wave-forces on intertidal organisms - a case-study. Limnol. Oceanogr. 30, 1171-1187.

Denny, M.W., 1995. Predicting physical disturbance: mechanistic approaches to the study of survivorship on wave swept shores. Ecol. Monogr. 65, 371-418.

Denny, M.W., Blanchette, C.A., 2000. Hydrodynamics, shell shape, behavior and survivorship in the owl limpet Lottia gigantea. J. Exp. Biol. 203, 2623-2639.

Denny, M.W., Daniel, T.L., Koehl, M.A.R., 1985. Mechanical limits to size in waveswept organisms. Ecol. Monogr. 55, 69-102.

Denny, M.W., Miller, L.P., Stokes, M.D., Hunt, L.J.H., Helmuth, B.S.T., 2003. Extreme water velocities: Topographical amplification of wave-induced flow in the surf zone of rocky shores. Limnol. Oceanogr. 48, 1-8. 
Denny, M.W., Helmuth, B., Leonard, G., Harley, C.D.G., Hunt, L.J.H., Nelson, E.K., 2004. Quantifying scale in ecology: lessons from a wave-swept shore. Ecol. Monogr. 74, 513-532.

Gaylord, B., 1999. Detailing agents of physical disturbance: wave-induced velocities and accelerations on a rocky shore. J. Exp. Mar. Biol. Ecol. 239, 85-124.

Gaylord, B., 2000. Biological implications of surf-zone flow complexity. Limnol. Oceanogr. 45, 174-188.

Hall, S.J., Raffaelli, D., R., T.W., 1990. Predator-caging experiments in marine systems: a reexamination of their value. Am. Nat. 136, 657-672.

Haven, S.B., 1973. Competition for food between the intertidal gastropods Acmaea scabra and Acmaea digitalis. Ecology 54, 143-151.

Hayworth, A.M., Quinn, J.F., 1990. Temperature of limpets in the rocky intertidal zone: Effects of caging and substratum. Limnol. Oceanogr. 35, 967-970.

Heisler, G.M., Dewalle, D.R., 1988. Effects of windbreak structure on wind flow. Agr. Ecosyst. Environ. 22-23, 41-69.

Helmuth, B., Denny, M.W., 2003. Predicting wave exposure in the rocky intertidal zone: Do bigger waves always lead to larger forces? Limnol. Oceanogr. 48, 1338-1345.

Hindell, J.S., Jenkins, G.P., Keough, M.J., 2001. Spatial and temporal variability in the effects of fish predation on macrofauna in relation to habitat complexity and cage effects. Mar. Ecol. Prog. Ser. 224, 231-250.

Hipsey, M.R., Sivapalan, M., 2003. Parameterizing the effect of a wind shelter on evaporation from small water bodies. Water Resour. Res. 39, 1339.

Hulberg, L.W., Oliver, J.S., 1980. Caging manipulations in marine soft-bottom communities: Importance of animal interactions or sedimentary habitat modifications. Can. J. Fish. Aquat. Sci. 37, 1130-1139.

Kennelly, S.J., 1983. An experimental approach to the study of factors affecting algal colonization in a sublittoral kelp forest. J. Exp. Mar. Biol. Ecol. 68, 257-276.

Kennelly, S.J., 1991. Caging experiments to examine the effects of fishes on understorey species in a sublittoral kelp community. J. Exp. Mar. Biol. Ecol. 147, 207-230.

Keuskamp, D., 2004. Limited effects of grazer exclusion on the epiphytes of Posidonia sinuosa in South Australia. Aquat. Bot. 78, 3-14.

Lassig, B.R., 1982. Determinants of the structure of small-scale coral patch reef fish assemblages. Dissertation, Maquarie University, Sydney, $230 \mathrm{pp}$.

Leber, K.M., 1985. The influence of predatory decapods, refuge, and microhabitat selection on seagrass communities. Ecology 66, 1951-1964.

Lowe, R.J., Koseff, J.R., Monismith, S.G., 2005. Oscillatory flow through submerged canopies: 1. Velocity structure. J. Geophys. Res., C 110, 1-17.

McNaughton, K.G., 1988. Effects of windbreaks on turbulent transport and microclimate. Agr. Ecosyst. Environ. 22-23, 17-39.

Menge, B.A., 1976. Organization of the New England rocky intertidal community: Role of predation, competition, and environmental heterogeneity. Ecol. Monogr. 46, 355-393.

Menge, B.A., 1978. Predation intensity in a rocky intertidal community: Relation between predator foraging activity and environmental harshness. Oecologia 34, 116. 
Menge, B.A., Lubchenco, J., Ashkenas, L.R., Ramsey, F., 1986. Experimental separation of effects of consumers on sessile prey in the low zone of a rocky shore in the Bay of Panama: Direct and indirect consequences of food web complexity. J. Exp. Mar. Biol. Ecol. 100, 225-269.

Menge, B.A., Blanchette, C., Raimondi, P., Freidenburg, T., Gaines, S., Lubchenco, J., Lohse, D., Hudson, G., Foley, M., Pamplin, J., 2004. Species interaction strength: Testing model predictions along an upwelling gradient. Ecol. Monogr. 74, 663684.

Menge, J.L., 1974. Prey selection and foraging period of the predaceous rocky intertidal snail, Acanthina punctulata. Oecologia 17, 293-316.

Miller, S.L., 1974. Adaptive design of locomotion and foot form in prosobranch gastropods. J. Exp. Mar. Biol. Ecol. 14, 99-156.

Navarrete, S.A., 1996. Variable predation: effects of whelks on a mid-intertidal successional community. Ecol. Monogr. 66, 301-321.

Olafsson, E.B., Peterson, C.H., Ambrose, W.G.J., 1994. Does recruitment limitation structure populations and communities of macro-invertebrates in marine soft sediments: the relative significance of pre- and post-settlement processes. Oceanogr. Mar. Biol. 32, 65-109.

Paine, R.T., 1977. Controlled manipulations in the marine intertidal zone, and their contributions to ecological theory. In: Goulden, C.E. (Ed.), Changing scenes in natural sciences 1776-1976. Academy of Natural Sciences of Philadelphia Special Publication, Philadelphia, pp. 245-270.

Peterson, C.H., 1979. Predation, competitive exclusion, and diversity in the soft-sediment benthic communities of estuaries and lagoons. In: Livingston, R.J. (Ed.),

Ecological processes in coastal and marine systems. Plenum Press, New York, pp. 233-264.

Quinn, G.P., Keough, M.J., 2002. Experimental design and data analysis for biologists. Cambridge University Press, Cambridge.

Schmidt, G.H., Warner, G.F., 1984. Effects of caging on the development of a sessile epifaunal community. Mar. Ecol. Prog. Ser. 15, 251-263.

Sokal, R.R., Rohlf, F.J., 1995. Biometry. W. H. Freeman and Company, New York.

Sousa, W.P., 2001. Natural disturbance and the dynamics of marine benthic communities. In: Bertness, M.D., S.D. Gaines, M.E. Hay (Eds.), Marine Community Ecology. Sinauer Associates, Inc., Sunderland, Massachusetts, pp. 85-130.

Strasser, M., 2002. Reduced epibenthic predation on intertidal bivalves after a severe winter in the European Wadden Sea. Mar. Ecol. Prog. Ser. 241, 113-123.

Tomanek, L., Sanford, E., 2003. Heat-shock protein 70 (Hsp 70) as a biochemical stress indicator: an experimental field test in two congeneric intertidal gastropods (Genus: Tegula). Biol. Bull. 205, 276-284.

Trussell, G.C., 1997. Phenotypic selection in an intertidal snail: Effects of a catastrophic storm. Mar. Ecol. Prog. Ser. 151, 73-79.

Underwood, A.J., 1997. Experiments in ecology. Cambridge University Press, Cambridge.

van Katwijk, M.M., Hermus, D.C.R., 2002. Effects of water dynamics on Zostera marina: transplantation experiments in the intertidal Dutch Wadden Sea. Mar. Ecol. Prog. Ser. 208, 107-118. 
Virnstein, R.W., 1977. The importance of predation by crabs and fishes on benthic infauna in Chesapeake Bay. Ecology 58, 1199-1217.

Virnstein, R.W., 1978. Predator caging experiments in soft sediments: caution advised. In: Wiley, M.L. (Ed.), Estuarine Interactions. Academic Press, New York, pp. 603.

Woodin, S.A., 1981. Disturbance and community structure in a shallow water sand flat. Ecology 62, 1052-1066. 
Table 1. ANOVA results for tests of mesh size on measured forces under cage structures in the laboratory water cannon. Each water velocity and structure type was tested separately, with five mesh sizes as the treatment levels. In each case, the wire structures reduced water velocities significantly compared to the control condition with no structure mounted over the force transducer.

\begin{tabular}{|c|c|c|c|c|c|c|c|}
\hline $\begin{array}{l}\text { Structure } \\
\text { Type }\end{array}$ & $\begin{array}{c}\text { Water speed } \\
\mathbf{m} / \mathbf{s}\end{array}$ & Source & SS & df & MS & F ratio & $\mathbf{p}$ \\
\hline Full cage & 5 & $\begin{array}{l}\text { Mesh Size } \\
\text { Error }\end{array}$ & $\begin{array}{l}3.05 \\
0.13\end{array}$ & $\begin{array}{c}5 \\
54\end{array}$ & $\begin{array}{c}0.61 \\
0.002\end{array}$ & 254.91 & $<0.001 *$ \\
\hline Full cage & 6.8 & $\begin{array}{l}\text { Mesh Size } \\
\text { Error }\end{array}$ & $\begin{array}{c}11.784 \\
1.230\end{array}$ & $\begin{array}{c}5 \\
54\end{array}$ & $\begin{array}{l}2.357 \\
0.023\end{array}$ & 103.45 & $<0.001 *$ \\
\hline Full cage & 10 & $\begin{array}{l}\text { Mesh Size } \\
\text { Error }\end{array}$ & $\begin{array}{c}33.14 \\
1.38\end{array}$ & $\begin{array}{c}5 \\
54\end{array}$ & $\begin{array}{c}6.63 \\
0.026\end{array}$ & 259.65 & $<0.001 *$ \\
\hline Full cage & 11.6 & $\begin{array}{l}\text { Mesh Size } \\
\text { Error }\end{array}$ & $\begin{array}{l}50.68 \\
1.80\end{array}$ & $\begin{array}{c}5 \\
54\end{array}$ & $\begin{array}{l}10.136 \\
0.033\end{array}$ & 303.24 & $<0.001 *$ \\
\hline Roof & 5 & $\begin{array}{l}\text { Mesh Size } \\
\text { Error }\end{array}$ & $\begin{array}{l}0.124 \\
0.006\end{array}$ & $\begin{array}{c}5 \\
54\end{array}$ & $\begin{array}{l}0.025 \\
0.000\end{array}$ & 209.34 & $<0.001 *$ \\
\hline Roof & 6.8 & $\begin{array}{l}\text { Mesh Size } \\
\text { Error }\end{array}$ & $\begin{array}{c}12.707 \\
1.061\end{array}$ & $\begin{array}{c}5 \\
54\end{array}$ & $\begin{array}{l}2.541 \\
0.020\end{array}$ & 129.394 & $<0.001 *$ \\
\hline Roof & 10 & $\begin{array}{l}\text { Mesh Size } \\
\text { Error }\end{array}$ & $\begin{array}{c}24.808 \\
1.272\end{array}$ & $\begin{array}{c}5 \\
54\end{array}$ & $\begin{array}{l}4.962 \\
0.024\end{array}$ & 210.678 & $<0.001^{*}$ \\
\hline Roof & 11.6 & $\begin{array}{l}\text { Mesh Size } \\
\text { Error }\end{array}$ & $\begin{array}{c}37.646 \\
0.821\end{array}$ & $\begin{array}{c}5 \\
54\end{array}$ & $\begin{array}{l}7.529 \\
0.015\end{array}$ & 495.153 & $<0.001^{*}$ \\
\hline
\end{tabular}


Table 2 Effect of structure style (cage or roof) on measured force in water cannon. ANOVAs are carried out for each water speed and mesh size separately. Where a significant difference in measured force is found, the structure style that produced the lower measured forces is indicated in the "Lower measured forces" column. Non-significant treatments indicate that the structure style causes an approximately equal reduction in measured force.

\begin{tabular}{|c|c|c|c|c|c|c|c|}
\hline $\begin{array}{l}\text { Water speed } \\
(\mathbf{m} / \mathbf{s})\end{array}$ & $\begin{array}{c}\text { Mesh } \\
\text { Size } \\
(\mathbf{m m})\end{array}$ & Source & df & MS & F-ratio & p-value & $\begin{array}{c}\text { Lower } \\
\text { measured } \\
\text { forces }\end{array}$ \\
\hline \multirow[t]{2}{*}{5} & 23 & Structure Style & 1 & $<0.001$ & 0.188 & 0.670 & \\
\hline & & Error & 18 & 0.002 & & & \\
\hline \multirow[t]{2}{*}{5} & 11.5 & Structure Style & 1 & 0.002 & 1.295 & 0.270 & \\
\hline & & Error & 18 & 0.001 & & & \\
\hline \multirow[t]{2}{*}{5} & 7 & Structure Style & 1 & 0.006 & 2.328 & 0.144 & \\
\hline & & Error & 18 & 0.003 & & & \\
\hline \multirow[t]{2}{*}{5} & 5 & Structure Style & 1 & 0.032 & 17.508 & $0.001 *$ & Cage \\
\hline & & Error & 18 & 0.002 & & & \\
\hline \multirow[t]{2}{*}{5} & 3 & Structure Style & 1 & 0.032 & 12.270 & $0.003^{*}$ & Cage \\
\hline & & Error & 18 & 0.003 & & & \\
\hline \multirow[t]{2}{*}{6.8} & 23 & Structure Style & 1 & 0.472 & 25.237 & $<0.001 *$ & Roof \\
\hline & & Error & 18 & 0.019 & & & \\
\hline \multirow[t]{2}{*}{6.8} & 11.5 & Structure Style & 1 & 0.007 & 0.621 & 0.441 & \\
\hline & & Error & 18 & 0.012 & & & \\
\hline \multirow[t]{2}{*}{6.8} & 7 & Structure Style & 1 & 0.005 & 0.563 & 0.463 & \\
\hline & & Error & 18 & 0.009 & & & \\
\hline \multirow[t]{2}{*}{6.8} & 5 & Structure Style & 1 & 0.007 & 0.535 & 0.474 & \\
\hline & & Error & 18 & 0.013 & & & \\
\hline \multirow[t]{2}{*}{6.8} & 3 & Structure Style & 1 & 0.215 & 13.949 & $0.002 *$ & Roof \\
\hline & & Error & 18 & 0.015 & & & \\
\hline \multirow[t]{2}{*}{10} & 23 & Structure Style & 1 & 0.127 & 5.235 & $0.034 *$ & Cage \\
\hline & & Error & 18 & 0.024 & & & \\
\hline \multirow[t]{2}{*}{10} & 11.5 & Structure Style & 1 & $<0.001$ & 0.026 & 0.873 & \\
\hline & & Error & 18 & 0.015 & & & \\
\hline \multirow[t]{2}{*}{10} & 7 & Structure Style & 1 & $<0.001$ & 0.001 & 0.981 & \\
\hline & & Error & 18 & 0.018 & & & \\
\hline \multirow[t]{2}{*}{10} & 5 & Structure Style & 1 & 1.194 & 46.981 & $<0.001 *$ & Cage \\
\hline & & Error & 18 & 0.025 & & & \\
\hline \multirow[t]{2}{*}{10} & 3 & Structure Style & 1 & 0.264 & 13.132 & $0.002 *$ & Cage \\
\hline & & Error & 18 & 0.020 & & & \\
\hline \multirow[t]{2}{*}{11.6} & 23 & Structure Style & 1 & $<0.001$ & 0.009 & 0.924 & \\
\hline & & Error & 18 & 0.030 & & & \\
\hline \multirow[t]{2}{*}{11.6} & 11.5 & Structure Style & 1 & 0.001 & 0.038 & 0.847 & \\
\hline & & Error & 18 & 0.017 & & & \\
\hline \multirow[t]{2}{*}{11.6} & 7 & Structure Style & 1 & 0.508 & 15.962 & $0.001 *$ & Cage \\
\hline & & Error & 18 & 0.032 & & & \\
\hline \multirow[t]{2}{*}{11.6} & 5 & Structure Style & 1 & 0.850 & 45.986 & $<0.001 *$ & Cage \\
\hline & & Error & 18 & 0.018 & & & \\
\hline \multirow[t]{2}{*}{11.6} & 3 & Structure Style & 1 & 0.322 & 29.212 & $<0.001 *$ & Cage \\
\hline & & Error & 18 & 0.011 & & & \\
\hline
\end{tabular}


Table 3 ANCOVA results for comparison of wave forces measured in the field on maximum-force recording dynamometers with and without cage structures covering the site. The offshore significant wave height is used as a covariate, the test is for the main effect of the treatment, presence or absence of a cage structure. Significant effects of the presence of a structure on wave forces are denoted with an asterisk. Structure sizes and designs are described in the text.

\begin{tabular}{|c|c|c|c|c|c|c|}
\hline $\begin{array}{c}\text { Structure } \\
\text { Type }\end{array}$ & Source & SS & df & MS & F-ratio & $\mathbf{p}$ \\
\hline \multicolumn{7}{|l|}{ Small cage } \\
\hline \multirow[t]{3}{*}{ Site 1} & Cage Presence/Absence & 241.56 & 1 & 241.56 & 1.31 & 0.257 \\
\hline & Wave Height & 817.42 & 1 & 817.42 & 4.44 & 0.04 \\
\hline & Error & 8450.73 & 46 & 183.71 & & \\
\hline \multirow[t]{3}{*}{ Site 2} & Cage Presence/Absence & 357.88 & 1 & 357.88 & 5.19 & $0.028 *$ \\
\hline & Wave Height & 2341.41 & 1 & 23.41 .41 & 33.96 & $<0.001$ \\
\hline & Error & 2895.73 & 42 & 68.95 & & \\
\hline \multicolumn{7}{|l|}{ Big cage } \\
\hline \multirow[t]{3}{*}{ Site 1} & Cage Presence/Absence & 20.47 & 1 & 20.47 & 0.384 & 0.539 \\
\hline & Wave Height & 1566.41 & 1 & 1566.41 & 29.356 & $<0.001$ \\
\hline & Error & 2401.12 & 45 & 53.35 & & \\
\hline \multirow[t]{3}{*}{ Site 2} & Cage Presence/Absence & 2211.78 & 1 & 2211.78 & 42.14 & $<0.001 *$ \\
\hline & Wave Height & 2334.44 & 1 & 2334.44 & 44.48 & $<0.001$ \\
\hline & Error & 2151.72 & 41 & 52.48 & & \\
\hline \multicolumn{7}{|l|}{ Roof } \\
\hline \multirow[t]{3}{*}{ Site 1} & Cage Presence/Absence & 76.70 & 1 & 76.70 & 1.723 & 0.196 \\
\hline & Wave Height & 1729.72 & 1 & 1729.72 & 38.84 & $<0.001$ \\
\hline & Error & 2048.46 & 46 & 44.53 & & \\
\hline \multirow[t]{3}{*}{ Site 2} & Cage Presence/Absence & 1302.96 & 1 & 1302.96 & 8.175 & $0.007 *$ \\
\hline & Wave Height & 3753.79 & 1 & 3753.79 & 23.55 & $<0.001$ \\
\hline & Error & 6694.32 & 42 & 159.38 & & \\
\hline \multicolumn{7}{|l|}{ Fence } \\
\hline \multirow[t]{3}{*}{ Site 1} & Cage Presence/Absence & 4.36 & 1 & 4.36 & 0.078 & 0.782 \\
\hline & Wave Height & 1780.41 & 1 & 1780.41 & 31.856 & $<0.001$ \\
\hline & Error & 2067.94 & 37 & 55.89 & & \\
\hline \multirow[t]{3}{*}{ Site 2} & Cage Presence/Absence & 2071.06 & 1 & 2071.06 & 21.24 & $<0.001 *$ \\
\hline & Wave Height & 2899.92 & 1 & 2899.92 & 29.746 & $<0.001$ \\
\hline & Error & 4094.51 & 42 & 97.48 & & \\
\hline
\end{tabular}




\section{Figure captions}

Figure 1. Schematic of the laboratory water cannon used for testing the effects of cages on water flow at high speeds. The operation of the water cannon is described in the text. The inset photograph shows water moving through and around a cage during the moment of impact.

Figure 2. Example set of velocity measurements conducted in subtidal habitats, comparing flows inside and outside of full cages constructed from a range of mesh sizes.

Figure 3. Example set of velocity measurements conducted in subtidal habitats, comparing flows inside and outside of fence structures constructed from a range of mesh sizes.

Figure 4. Example set of velocity measurements conducted in subtidal habitats, comparing flows inside and outside of roof structures constructed from a range of mesh sizes.

Figure 5. Slopes of the linear regressions of Figs. 2-4, versus the percentage of open area in the mesh used to construct the full cages, fences, and roofs. Circles = full cages; triangles $=$ fences $;$ diamonds $=$ roofs; crosses $=$ no cage structure .

Figure 6. Average forces measured with force transducer under wire mesh structures mounted in the laboratory water cannon. Control data had no structure mounted over the 
transducer. Data are grouped by the free stream water velocity $\left(5.1,6.8,10,11.6 \mathrm{~m} \mathrm{~s}^{-1}\right)$ and by structure type. Lines over bars indicate treatments which were not significantly different from each other as tested by an ANOVA and post-hoc Tukey test. All other bars are significantly different from each other $(\mathrm{n}=10, \mathrm{p}<0.001)$ within one water speed. A) Cage treatment, structure has four mesh sides and a mesh top. B) Roof treatment, structure has two mesh sides and a mesh top. A mesh side faces the oncoming water flow. Error bars represent $95 \%$ confidence intervals.

Figure 7. Water velocities inside of cage structures relative to velocities without a structure present, using the laboratory water cannon. Each structure was tested ten times at each speed. A) Full cages constructed of five mesh sizes. B) Roof structures constructed of five mesh sizes. The closed mesh side of the roof faced the oncoming flow.

Figure 8 . Forces measured by maximum-force recording dynamometers at two representative field sites. A fence with $5 \mathrm{~mm}$ mesh was placed around the dynamometer (closed circles) for several weeks, and control wave force data (open circles) were recorded at the same site for several weeks as well. At site 1 there was a significant effect of the presence of the fence on measured forces (ANCOVA with offshore wave height as the covariate, $\left.\mathrm{F}_{1,42}=21.24, \mathrm{p}<0.001\right)$. At site 2 , there was no significant difference between the measured wave forces during the two time periods. The same pattern of significant effects at one site and no significant effect at a second site held for each of the other three structures tested, and those data are not shown here. 
Figure 1.

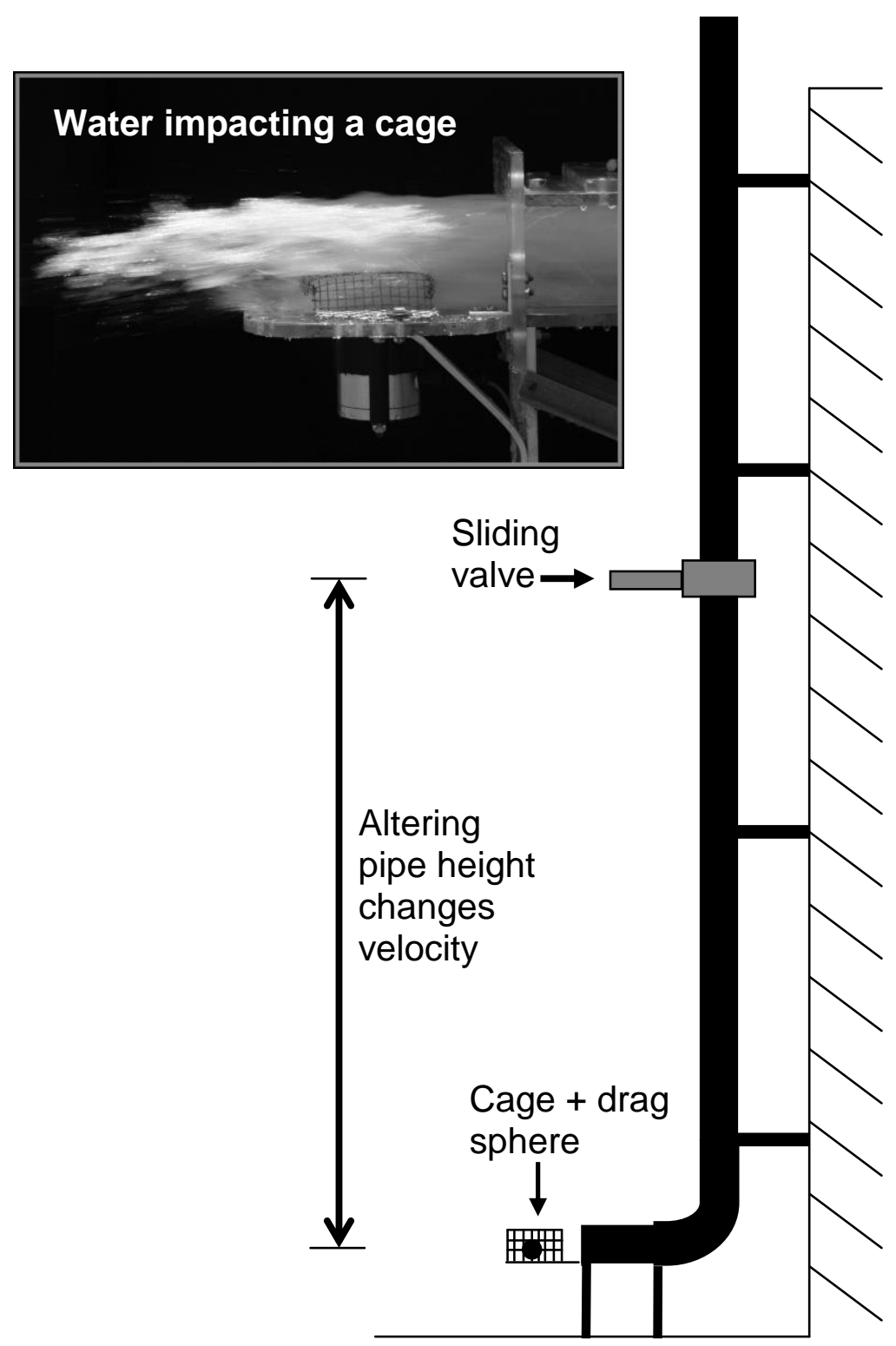


Figure 2.

a)

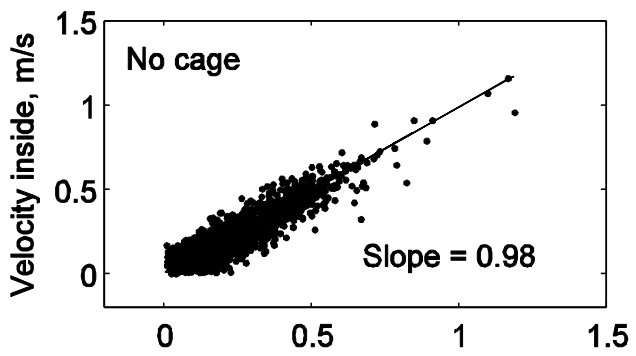

b) Velocity outside, $\mathrm{m} / \mathrm{s}$

c)

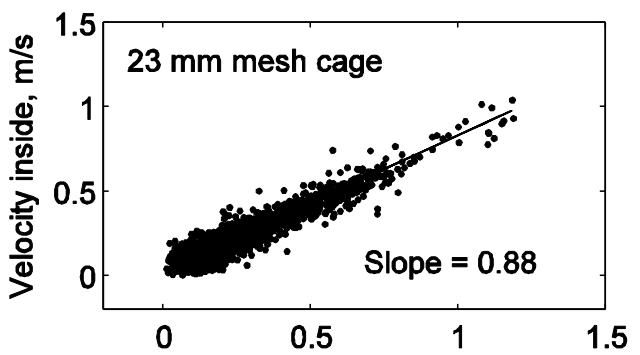

d)

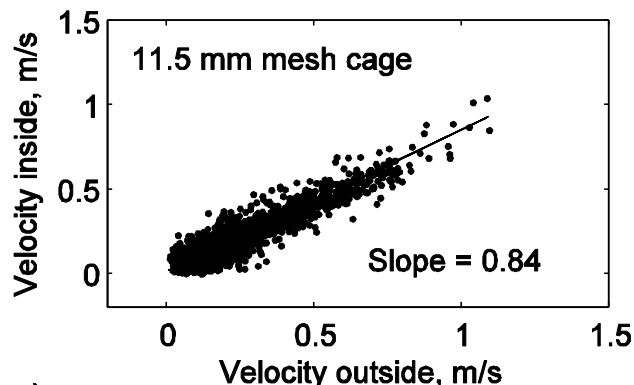

e)
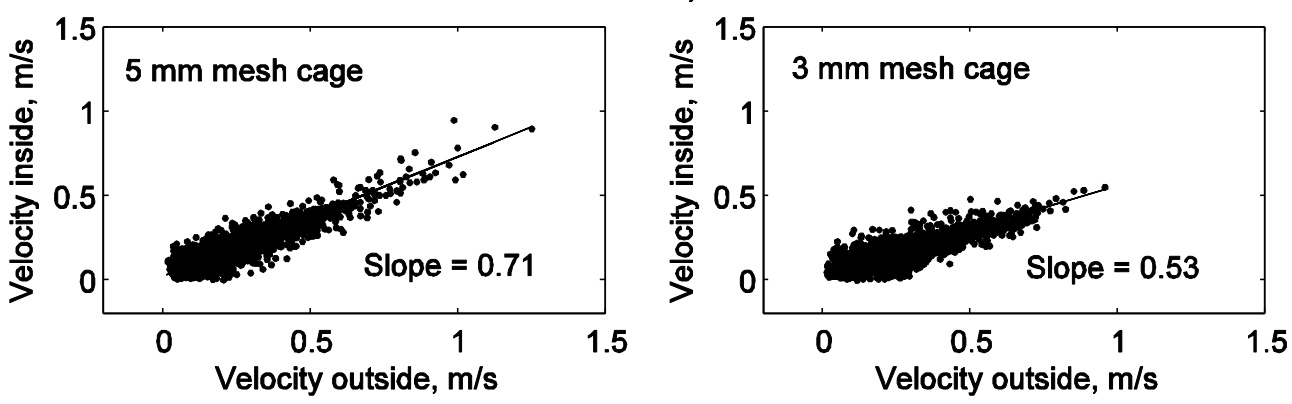
Figure 3.

a)

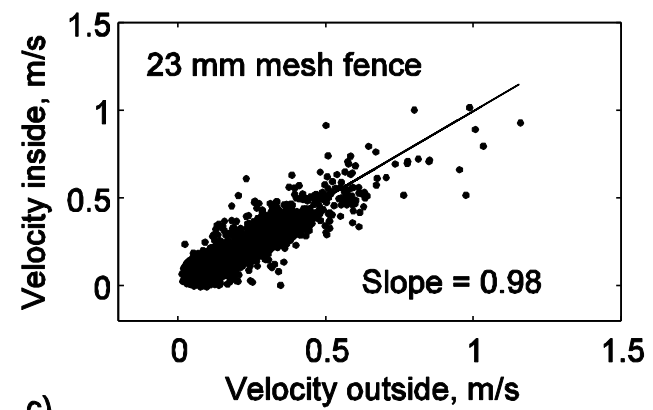

c)

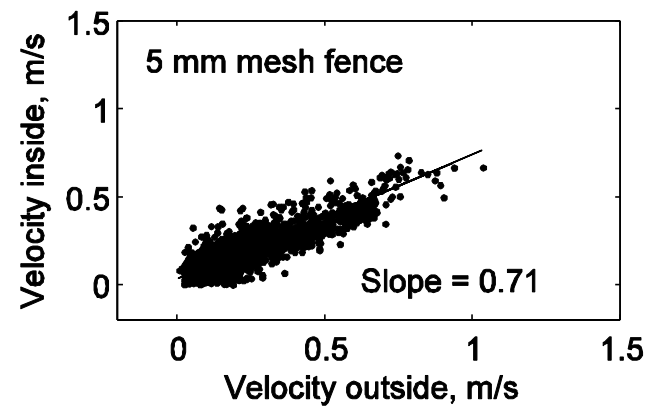

b)

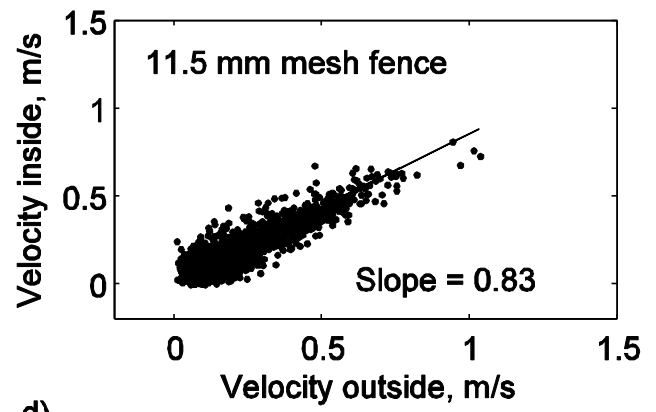

d)

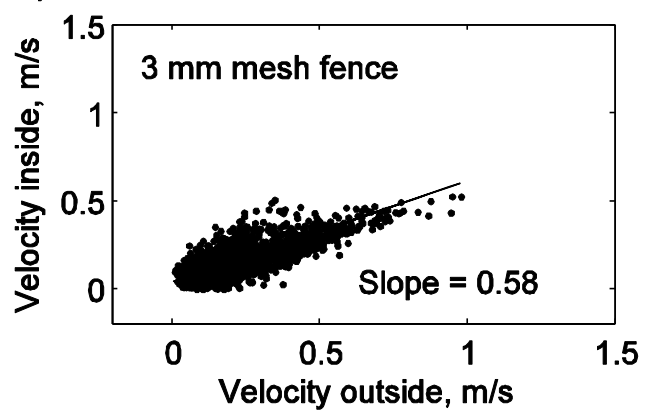


Figure 4.

a)

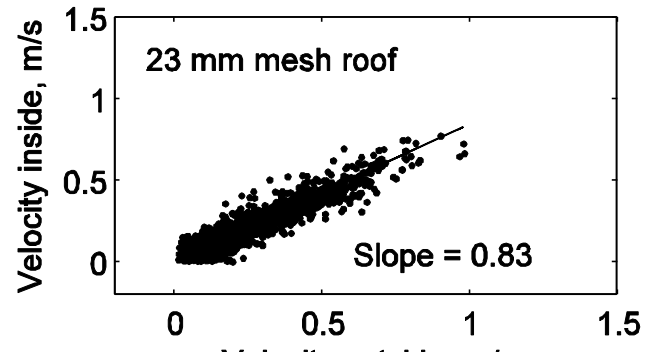

c)

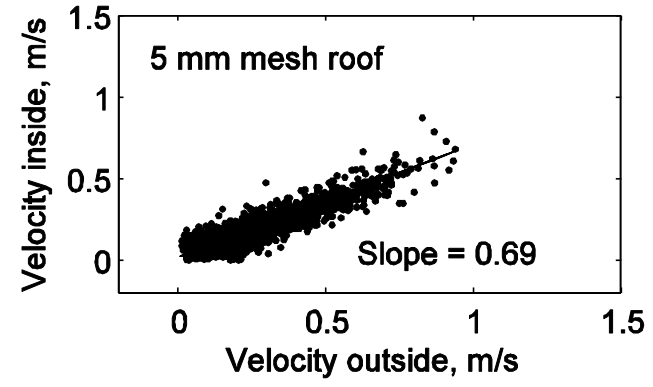

b)

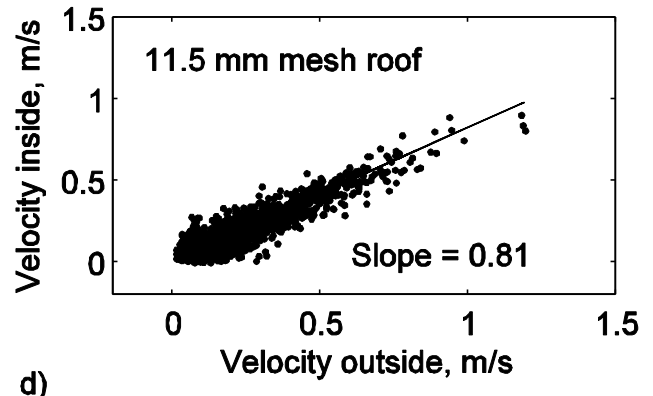

d)

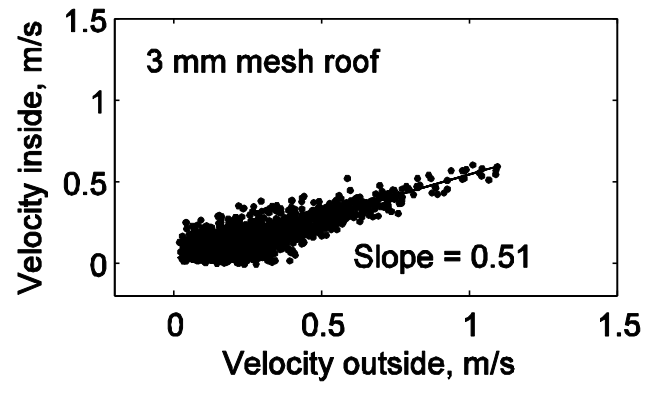


Figure 5.

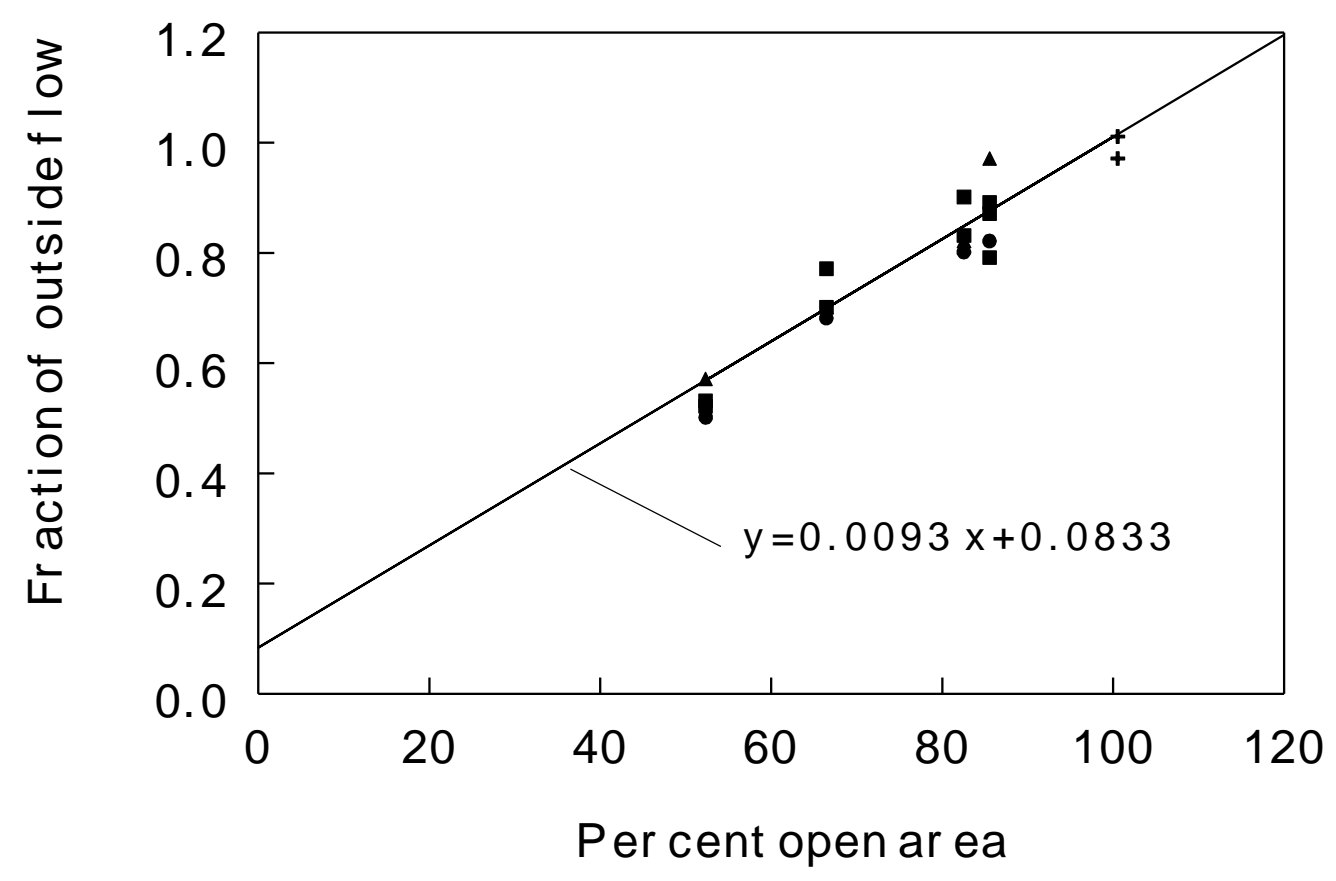


Figure 6.

\section{A. Cage Treatment}

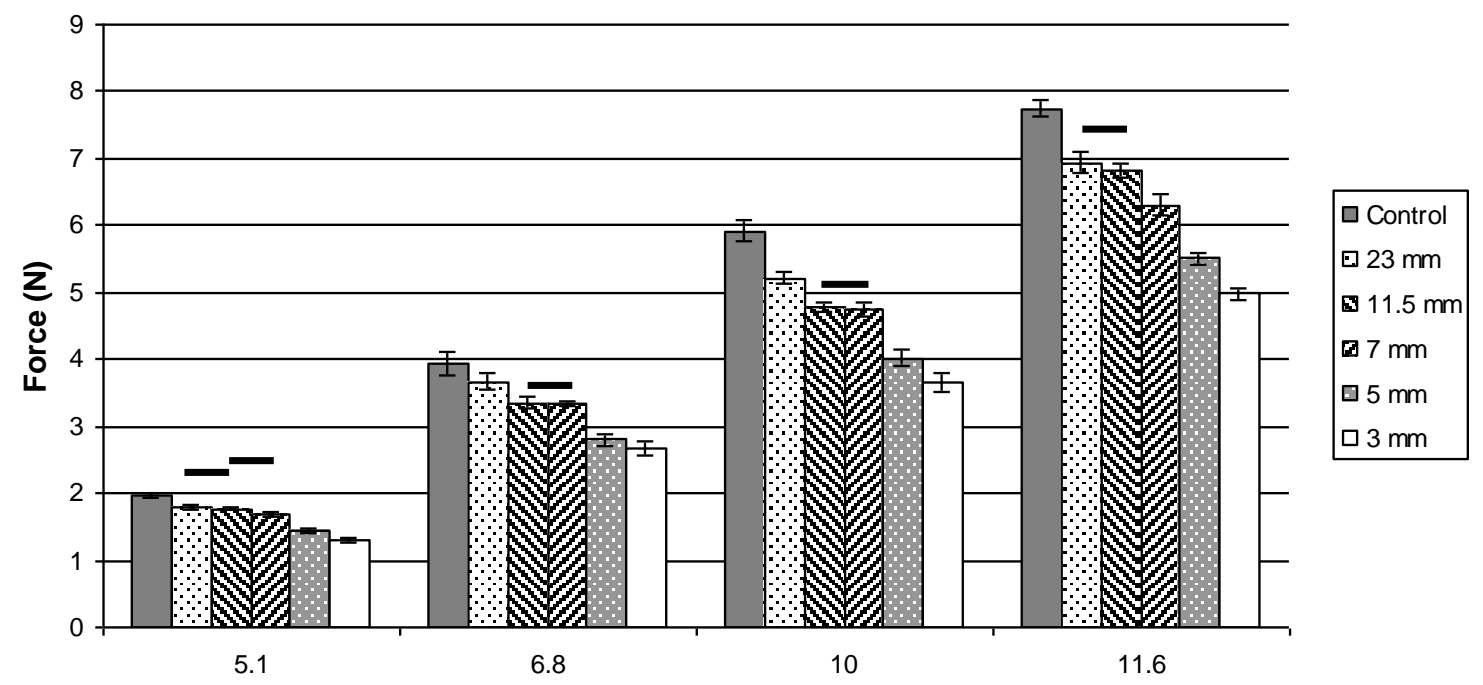

B. Roof Treatment

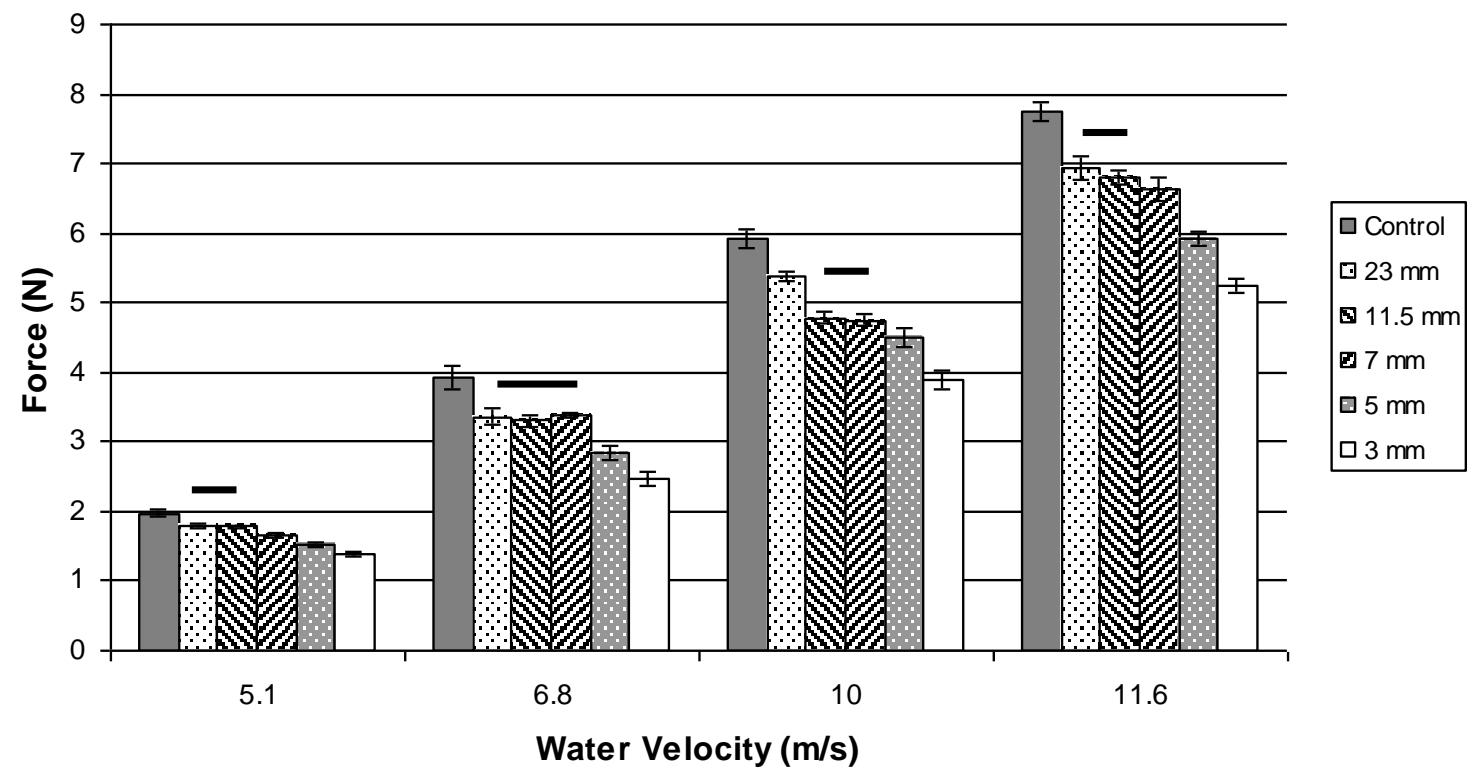


Figure 7

a.
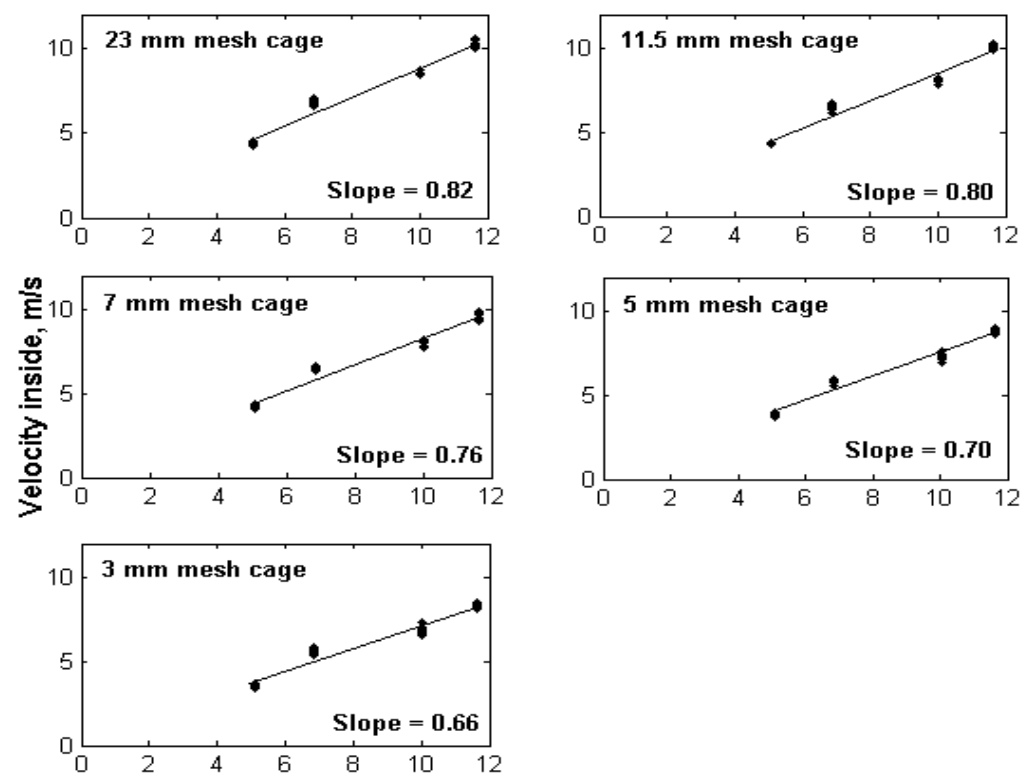

Velocity outside, $\mathrm{m} / \mathrm{s}$

b.
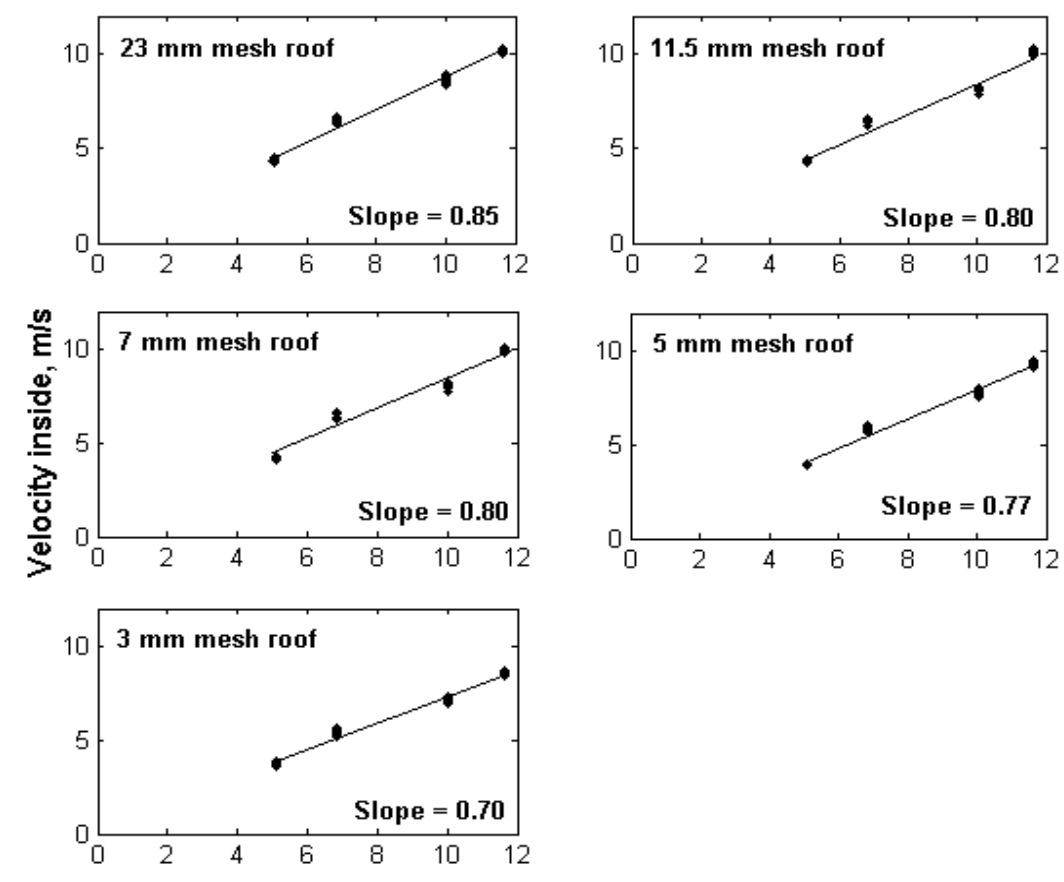

Velocity outside, m/s 
Figure 8.

Site 1

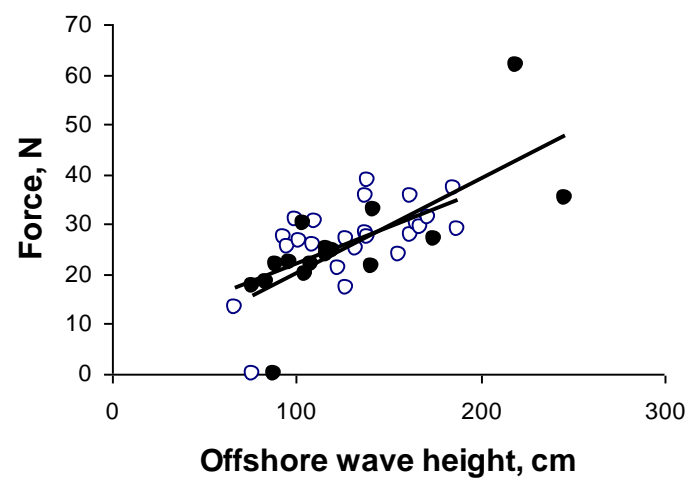

Site 2

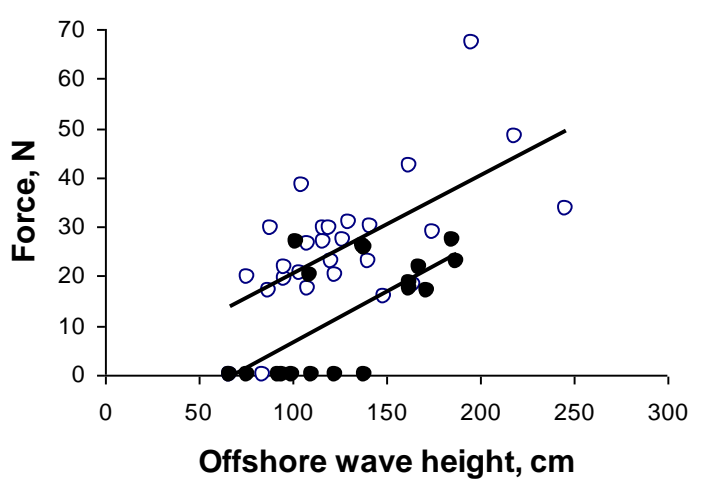

